\title{
Post-anesthesia care unit desaturation in adult deep extubation patients
}

\author{
Jeremy Juang ${ }^{1,2^{*}+} \mathbb{D}$, Martha Cordoba ${ }^{1,2+}$, Mark Xiao ${ }^{1,2}$, Alex Ciaramella ${ }^{1,2}$, Jeremy Goldfarb ${ }^{1,2}$, \\ Jorge Enrique Bayter ${ }^{3}$ and Alvaro Andres Macias ${ }^{1,2}$
}

\begin{abstract}
Objective: Deep extubation refers to endotracheal extubation performed while a patient is deeply anesthetized and without airway reflexes. After deep extubation, patients are sent to the post-anesthesia care unit (PACU) to recover, an area with notably different management and staffing than the operating room (OR). One of the most frequent and concerning complications to occur in the PACU is hypoxemia. As such, this study seeks to evaluate the incidence of desaturation, defined by $\mathrm{SpO} 2<90 \%$ for longer than $10 \mathrm{~s}$, in the PACU following deep extubation. Additionally, we hope to assess the consequence of desaturation on perioperative workflow by comparing PACU recovery times.

Results: Following deep extubation, 4.3\% of patients (13/300) experienced desaturation in the PACU. Every episode was notably minor, with patients reverting to normal saturation levels within a minute. Of the 26 case factors assessed, 24 had no significant association desaturation in the PACU, including the amount of time spent in the PACU. History of asthma was the only statistically significant factor found to be positively associated with desaturation. We find that PACU desaturation episodes following deep extubation are rare. Our findings suggest that deep extubation is a viable and safe option for patients without significant respiratory tract pathology.
\end{abstract}

Keywords: Deep extubation, Respiratory pathology, Anesthesia, Ambulatory surgery, PACU workflow, Desaturation

\section{Introduction}

Compared to traditional endotracheal extubation, deep extubation can be advantageous because of its potential for a "smooth" emergence from anesthesia. Patients, without return of their airway reflexes, are less inclined to buck or cough. This is particularly important in procedures requiring the maintenance of stable intraocular and intracranial pressures, such as in neurologic, ophthalmic, and head-and-neck surgery [1]. After extubation, patients are sent to recover in the post-anesthesia care unit (PACU).

\footnotetext{
*Correspondence: jeremy_juang@meei.harvard.edu

${ }^{\dagger} J$ Jeremy Juang and Martha Cordoba contributed equally to the manuscript

${ }^{1}$ Department of Anesthesiology, Massachusetts Eye and Ear, 243 Charles

St, Boston, MA 02114, USA

Full list of author information is available at the end of the article
}

PACU staff monitor the patient's overall condition before discharge or transfer. Though anesthesia providers are present, most staffing typically consists of Registered Nurses (RNs), and the provider to patient ratio is lower relative to the operating room (OR). As a result, the PACU is less equipped to deal with airway complications. Critical incidents can prolong patients' length of stay (LOS), which in turn disrupts the OR schedule, creating back-ups and inefficiencies in resource utilization [2-4]. Desaturation events are common and of particular concern; up to $26.3 \%$ of hypoxemic events in the PACU may remain unresolved for over $10 \mathrm{~min}$, leading to increased risks of future clinical deterioration $[5,6]$.

Though literature regarding desaturation in the PACU exists, it is lacking in the context of deep extubation. Thus, this study describes the occurrence of desaturation $(\mathrm{SpO} 2<90 \%,>10 \mathrm{~s})$ following deep extubation. Our objective was to determine whether different case factors

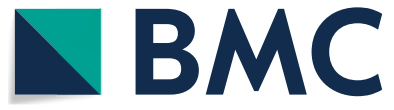

(c) The Author(s) 2021. This article is licensed under a Creative Commons Attribution 4.0 International License, which permits use, sharing, adaptation, distribution and reproduction in any medium or format, as long as you give appropriate credit to the original author(s) and the source, provide a link to the Creative Commons licence, and indicate if changes were made. The images or other third party material in this article are included in the article's Creative Commons licence, unless indicated otherwise in a credit line to the material. If material is not included in the article's Creative Commons licence and your intended use is not permitted by statutory regulation or exceeds the permitted use, you will need to obtain permission directly from the copyright holder. To view a copy of this licence, visit http://creativecommons.org/licenses/by/4.0/. The Creative Commons Public Domain Dedication waiver (http://creativecommons.org/publicdomain/zero/1.0/) applies to the data made available in this article, unless otherwise stated in a credit line to the data. 
contribute to the incidence of desaturation and the effect of desaturation on time spent in PACU recovery.

The data presented here is an extension of the research article by Juang et al. on the Incidence of Airway Complications Associated with Deep Extubation in Ambulatory Ophthalmic and Head-and-Neck Surgery in Adults [7].

\section{Main text \\ Materials and methods Study population}

This study used data from the single-arm, unblinded, observational deep extubation study by Juang and colleagues. [7]. Briefly, a total of three hundred patients over eighteen years old were enrolled over six months with no specific exclusion criterion. Data were collected towards the end of surgery on patients identified by a research coordinator as deep extubation candidates. These patients were followed from the end of surgery (in the OR) to PACU discharge for data collection.

\section{Ethics}

The study was approved by the Institutional Review Board (IRB) of Massachusetts Eye and Ear Infirmary and was registered at Clinicaltrials.gov. As the research study involves no more than minimal risk to patients, the IRB waived the need to obtain written informed consent.

\section{Data collection}

Patient age, sex, BMI, type of surgery, ASA PS classification, Mallampati's class, respiratory tract pathology and infection, intubation record, and PACU times were extracted from an electronic medical record. Detailed PACU desaturation events (defined by $\mathrm{SpO} 2<90 \%$ for longer than $10 \mathrm{~s}$ ) and vital signs were collected prospectively by the research coordinator.

\section{Statistical analysis}

Patients were classified into two groups: those with desaturation events in the PACU and those without. Patient demographics, characteristics, procedure types, intubation records, and intraoperative variables were analyzed. Statistical analyses were performed using SAS software version 9.4 (SAS Institute, Cary, NC). Continuous variables were summarized using median and interquartile ranges (q1-q3), while categorical variables were summarized using frequencies and percentages. Wilcoxon rank-sum tests were used to compare continuous variables among groups. Chi-square tests (Fisher's exact test for small samples) were used to compare categorical variables among groups.

\section{Results}

A total of 300 patients were examined in this study. Desaturation, as defined in the data collection section under materials and methods, was observed in 13 out of $300(4.3 \%)$ patients.

When comparing patient demographics between the desaturation and the no-desaturation groups, no significant difference was found in age, sex, and BMI. Similarly, no significant difference was found when comparing the type of surgery (ear, eye, neck, nose, throat, thyroid), ASA PS classification, Mallampati's class, and Cormack and Lehane's grade.

History of asthma was found to be comparatively noteworthy, with the desaturation group having a significantly larger percentage of patients with asthma than the nodesaturation group $(46.15 \%$ vs. $17.77 \% \mathrm{p}=0.0210)$. The no-desaturation group, as compared to the desaturation group, was disproportionately composed of patients with no history of respiratory tract pathology $(61.32 \%$ vs. $23.08 \%, p=0.0082$ ). No other respiratory pathology tested (Chronic cough, OSA, recent respiratory tract infection, chronic obstructive pulmonary disease (COPD), current smoker) was found to be statistically significant.

Prevalence of comorbidities (none, diabetes, GI obstruction, hiatal hernia, gastroesophageal reflux disease (GERD)), Laryngoscopy device used (Glidescope, Macintosh blade, Miller blade, Other), and the number of direct Laryngoscopy attempts were not significantly different when comparing the desaturation and no-desaturation groups.

Finally, there was no significant difference in time spent in phase $1 \mathrm{PACU}$ (75 vs. $70 \mathrm{~min}, \mathrm{p}=0.3253$ ) nor phase 2 PACU (59.0 vs. $74.5 \mathrm{~min}, \mathrm{p}=0.3549$ ) when comparing the desaturation and the no-desaturation groups.

\section{Discussion}

Desaturation events are a major concern in the PACU, leading to time and resource inefficiencies, and potentially more severe postoperative respiratory complications $[8,9]$. As such, we chose it as the primary metric to judge the viability of deep extubation after release from the OR. The prevalence of desaturation $(\mathrm{SpO} 2<90 \%,>10 \mathrm{~s})$ in adults in the PACU was found to be $4.3 \%$. Interestingly, no significant difference was observed in Phase 1 and Phase 2 PACU recovery time. A probable explanation for this phenomenon is that all instances of desaturation lasted for less than a minute, 
and drastic, time-consuming interventions such as reintubation were neither necessary nor performed.

The $4.3 \%$ rate observed in our study is lower, but within the range of a previous study by Kaushal et al., which reported a desaturation incidence of $13.5 \%$ [10]. It is also consistent with an investigation by Smith et al., who reported a range of 1.1-13.3\% [11]. The difference in study methods may account for the higher rates reported. These studies utilized a lower alarm limit of $\leq 94 \%$, while we defined desaturation as $<90 \%$. In Smith's study, no patients were found to have a $\mathrm{SpO} 2<90 \%$. Additionally, in both of these studies, patients remained on room air until desaturation, while the providers in our study were able to preemptively intervene as they saw fit.

While most literature discusses COPD as the primary indication of potential desaturation, our study found asthma to be the only statistically significant condition. While asthma is traditionally considered reversible when compared to COPD, recent studies suggest that COPD exhibits moderate reversibility when treated with anticholinergics or $\beta 2$ agonists [12]. It must also be noted that COPD and recent respiratory tract infection, while not statistically significant, had p-values of 0.0642 and 0.0849 . The number of patients in the study with a history of respiratory tract pathology was small, so further investigation may be warranted.

Our findings indicate that deep extubation is associated with a low rate $(4.3 \%)$ of desaturation in the care of an experienced PACU team. Combined with similar PACU recovery times for both patients who did and did not experience desaturation, our data suggest that deep extubation for patients without significant respiratory tract

Table 1 Comparison of patient and case characteristics in the Post-Anesthesia Care Unit (PACU) between desaturation and no-desaturation groups. Data are expressed as median (q1-q3)

\begin{tabular}{|c|c|c|c|c|}
\hline \multirow[t]{2}{*}{ Characteristics } & \multirow[t]{2}{*}{ Total $(n=300)$} & \multicolumn{2}{|c|}{ PACU Desaturations } & \multirow[t]{2}{*}{ P-value } \\
\hline & & Yes $(n=13,4.3 \%)$ & No $(n=287,95.7 \%)$ & \\
\hline Age, median (q1-q3) & $50.0(31.0-61.5)$ & $38.0(29.0-55.0)$ & $50.0(31.5-62.0)$ & 0.1569 \\
\hline Male, n (\%) & $139(46.3 \%)$ & $6(46.15)$ & $133(46.34)$ & 0.9894 \\
\hline Body mass index in kg/m2, median (q1-q3) & $26.4(23.1-29.8)$ & $28.0(25.3-32.7)$ & $25.9(23.0-29.8)$ & 0.1755 \\
\hline \multicolumn{5}{|l|}{ Surgery class } \\
\hline Ear & $53(17.7)$ & $3(23.08)$ & $50(17.42)$ & \multirow[t]{6}{*}{0.0890} \\
\hline Eye & $15(5.0)$ & $0(0.0)$ & $15(5.23)$ & \\
\hline Neck & $50(16.7)$ & $0(0.0)$ & $50(17.42)$ & \\
\hline Nose & $87(29.0)$ & $8(61.54)$ & $79(27.53)$ & \\
\hline Throat & $73(24.3)$ & $1(7.69)$ & $72(25.09)$ & \\
\hline Thyroid & $22(7.3)$ & $1(7.69)$ & $21(7.32)$ & \\
\hline \multicolumn{5}{|l|}{ ASA } \\
\hline 1 & $65(21.7)$ & $4(30.77)$ & $61(21.25)$ & \multirow[t]{3}{*}{0.7288} \\
\hline 2 & $208(69.3)$ & $8(61.54)$ & $200(69.69)$ & \\
\hline 3 & $27(9.0)$ & $1(7.69)$ & $26(9.06)$ & \\
\hline \multicolumn{5}{|l|}{ Mallampati's class $(n=295)$} \\
\hline 1 & $114(38.6)$ & $4(30.77)$ & $110(39.01)$ & \multirow[t]{4}{*}{0.7576} \\
\hline 2 & $142(48.1)$ & $8(61.54)$ & $134(47.52)$ & \\
\hline 3 & $36(12.2)$ & $1(7.69)$ & $35(12.41)$ & \\
\hline \multirow[t]{2}{*}{4} & $3(1.0)$ & $0(0.0)$ & $3(1.06)$ & \\
\hline & $1(0.3)$ & $0(0.0)$ & $1(0.35)$ & 1.0000 \\
\hline \multicolumn{5}{|l|}{ Respiratory tract pathology history } \\
\hline None & $179(59.7)$ & $3(23.08)$ & $176(61.32)$ & $0.0082^{*}$ \\
\hline Asthma & $57(19.0)$ & $6(46.15)$ & $51(17.77)$ & $0.0210^{*}$ \\
\hline Chronic cough & $1(0.3)$ & $0(0.0)$ & $1(0.35)$ & 1.0000 \\
\hline OSA & $29(9.7)$ & $2(15.38)$ & $27(9.41)$ & 0.3636 \\
\hline Snoring & $33(11.0)$ & $2(15.38)$ & $31(10.80)$ & 0.6422 \\
\hline Recent respiratory tract infection within past 4 weeks & $2(0.7)$ & $1(7.69)$ & $1(0.35)$ & 0.0849 \\
\hline COPD & $10(3.3)$ & $2(15.38)$ & $8(2.79)$ & 0.0642 \\
\hline Current smoker & $26(8.7)$ & $2(15.38)$ & $24(8.36)$ & 0.3129 \\
\hline
\end{tabular}


Table 1 (continued)

\begin{tabular}{|c|c|c|c|c|}
\hline \multirow[t]{2}{*}{ Characteristics } & \multirow[t]{2}{*}{ Total $(n=300)$} & \multicolumn{2}{|c|}{ PACU Desaturations } & \multirow[t]{2}{*}{ P-value } \\
\hline & & Yes $(n=13,4.3 \%)$ & No $(n=287,95.7 \%)$ & \\
\hline \multicolumn{5}{|l|}{ Cormack and Lehane's grade $(n=298)$} \\
\hline 1 & $245(82.2)$ & $11(84.62)$ & $234(82.11)$ & \multirow[t]{5}{*}{1.0000} \\
\hline 2 & $48(16.1)$ & $2(15.38)$ & $46(16.14)$ & \\
\hline 3 & $4(1.3)$ & $0(0.0)$ & $4(1.40)$ & \\
\hline 4 & $1(0.3)$ & $0(0.0)$ & $1(0.35)$ & \\
\hline Difficulty intubation & $0(0.0)$ & $0(0.0)$ & $0(0.0)$ & \\
\hline \multicolumn{5}{|l|}{ Comorbidity } \\
\hline None & $220(73.3)$ & $9(69.23)$ & $211(73.52)$ & 0.7516 \\
\hline Diabetes & $25(8.3)$ & $1(7.69)$ & $24(8.36)$ & \multirow[t]{2}{*}{1.0000} \\
\hline Gl obstruction & $0(0.0)$ & $0(0.0)$ & $0(0.0)$ & \\
\hline Hiatal Hernia & $2(0.7)$ & $0(0.0)$ & $2(0.70)$ & 1.0000 \\
\hline GERD & $63(21.0)$ & $4(30.77)$ & $59(20.56)$ & 0.4830 \\
\hline \multicolumn{5}{|l|}{ Laryngoscopy device used } \\
\hline Glidescope & $51(17.0)$ & $2(15.38)$ & $49(17.07)$ & 1.0000 \\
\hline MAC & $236(78.7)$ & $11(84.62)$ & $225(78.40)$ & 0.7421 \\
\hline Miller & $12(4.0)$ & $0(0.0)$ & $12(4.18)$ & \multirow[t]{2}{*}{1.0000} \\
\hline Other & $0(0.0)$ & $0(0.0)$ & $0(0.0)$ & \\
\hline \multicolumn{5}{|l|}{ Number of direct laryngoscopy attempts $(n=293)$} \\
\hline 1 & $277(94.5)$ & $13(100.00)$ & $264(94.29)$ & \multirow[t]{3}{*}{1.0000} \\
\hline 2 & $13(4.4)$ & $0(0.0)$ & $13(4.64)$ & \\
\hline 3 & $3(1.0)$ & $0(0.0)$ & $3(1.07)$ & \\
\hline Phase 1 PACU in min, median ( $q 1-q 3), n=269$ & $70(58-88)$ & $75(59-118)$ & $70(58-87)$ & 0.3253 \\
\hline Phase 2 PACU in min, median (q1-q3), $n=222$ & $74(58-101)$ & $59.0(48.3-101.0)$ & $74.5(58.3-100.8)$ & 0.3549 \\
\hline
\end{tabular}

* Statistical significance with P-value $<0.05$

pathology is a safe and viable alternative to traditional awake endotracheal extubation.

\section{Limitations}

1. The study could not be blinded as the anesthesiologists and research staff are required to manage and observe the deep extubation technique.

2. Since none of the patients with a history of difficult airway underwent deep extubation due to safety concerns could lead to inherent selection bias

3. Experienced PACU nursing providers remained with each patient until adequate control of the airway was achieved, contributing to the low incidence rate of desaturationc (Table 1).

\footnotetext{
Abbreviations

ASA PS: American Society of Anesthesiologists Physical Status; BMI: Body Mass Index; COPD: Chronic obstructive pulmonary disease; FiO2: Fraction of inspired oxygen; GA: General anesthesia; GERD: Gastroesophageal reflux disease; IRB: Institutional review board; LOS: Length of stay; MEEI: Massachusetts eye and ear infirmary; OR: Operating room; PACU: Post-Anesthesia Care Unit; RN: Registered nurses; $\mathrm{SpO}_{2}$ : Saturation of peripheral oxygen.
}

\author{
Acknowledgements \\ We thank Xinling Xu for providing statistical support.
}

\section{Authors' contributions}

JJ: supervision, project administration, validation, formal analysis, investigation, data curation, writing-original draft, writing- review \& editing. Attestation: JJ approved the final manuscript and attested to the study report's integrity presented in this manuscript. Contribution: MC: Conceptualization, methodology, investigation, supervision, data curation, validation, writing-original draft, and writing- review \& editing. Attestation: MC approved the final manuscript and attested to the integrity of the study presented in this manuscript. Contribution: MX: data analysis, writing-original draft, and writing- review \& editing. Attestation: MX approved the final manuscript and attested to the integrity of the study presented in this manuscript. Contribution: AC: investigation, data curation, and validation. Attestation: AC approved the final manuscript and attested to the integrity of the study presented in this manuscript. Contribution: JG: Supervision, investigation, data curation, validation, interpretation, writing-original draft, writing- review \& editing. Attestation: JG approved the final manuscript and attested to the integrity of the study presented in this manuscript. Contribution: JEB: Conceptualization and methodology. Attestation: JEB approved the final manuscript and attested to the integrity of the study presented in this manuscript. Contribution: AAM: Conceptualization, methodology, investigation, data curation, validation, formal analysis, writingoriginal draft, writing- review \& editing, supervision, project administration, and funding acquisition. Principal Investigator. Attestation: AAM approved the final manuscript and attested to the integrity of the study presented in this manuscript.

Funding

The authors received no funding for this study. 


\section{Availability of data and materials}

The datasets used and analyzed during the current study available from the corresponding author on reasonable request.

\section{Declarations}

Ethics approval and consent to participate

The study (\#1047249) was approved by the MEEI IRB and received a waiver of written informed consent.

\section{Consent for publication}

Not applicable.

\section{Competing interests}

The authors declare that they have no known competing financial interests or personal relationships which have, or could be perceived to have, influenced the work reported in this article.

\section{Author details}

${ }^{1}$ Department of Anesthesiology, Massachusetts Eye and Ear, 243 Charles St, Boston, MA 02114, USA. ${ }^{2}$ Harvard Medical School, Boston, MA 20114, USA.

${ }^{3}$ Director Medico, Km 2 Anillo Vial Floridablanca - Girón, Clinica El PinarEcoparque Empresarial Natura Torre 2 piso 1 y 2, Piedecuesta, Colombia.

Received: 10 December 2020 Accepted: 8 April 2021

Published online: 20 April 2021

\section{References}

1. Kempen P. Extubation in adult patients: who, what, when, where, how, and why? J Clin Anesth. 1999;11(6):441-4.

2. Lalani SB, Ali F, Kanji Z. Prolonged-stay patients in the PACU: a review of the literature. J Perianesth Nurs. 2013;28(3):151-5.

3. Seago JA, Weitz S, Walczak S. Factors influencing stay in the post-anesthesia care unit: a prospective analysis. J Clin Anesth. 1998;10(7):579-87.
4. Bruins SD, Leong PM, Ng SY. Retrospective review of critical incidents in the post-anaesthesia care unit at a major tertiary hospital. Singapore Med J. 2017;58(8):497-501.

5. Epstein RH, Dexter F, Lopez MG, Ehrenfeld JM. Anesthesiologist staffing considerations consequent to the temporal distribution of hypoxemic episodes in the post-anesthesia care unit. Anesth Analg 2014;119(6):1322-33.

6. Mann-Farrar J, Egan E, Higgins A, Wysocki L, Vaux A, Arndell E, Burmeister EA. Are postoperative clinical outcomes influenced by length of stay in the postanesthesia care unit? J Perianesth Nurs. 2019;34(2):386-93.

7. Juang J, Cordoba M, Ciaramella A, Xiao M, Goldfarb J, Bayter JE, Macias AA. Incidence of airway complications associated with deep extubation in adults. BMC Anesthesiol. 2020;20(1):274.

8. Dimick JB, Chen SL, Taheri PA, Henderson WG, Khuri SF, Campbell DA Jr. Hospital costs associated with surgical complications: a report from the private-sector National Surgical Quality Improvement Program. J Am Coll Surg. 2004;199(4):531-7.

9. Ramachandran SK, Thompson A, Pandit JJ, Devine S, Shanks AM. Retrospective observational evaluation of postoperative oxygen saturation levels and associated postoperative respiratory complications and hospital resource utilization. PLoS ONE. 2017;12(5):e0175408.

10. Kaushal A, Goyal P, Dhiraaj S, Agarwal A, Singh PK. Identification of various perioperative risk factors responsible for development of postoperative hypoxaemia. Turk J Anaesthesiol Reanim. 2018;46(6):416-23.

11. Smith DC, Canning JJ, Crul JF. Pulse oximetry in the recovery room. Anaesthesia. 1989;44(4):345-8.

12. Louie S, Zeki AA, Schivo M, Chan AL, Yoneda KY, Avdalovic M, Morrissey $\mathrm{BM}$, Albertson TE. The asthma-chronic obstructive pulmonary disease overlap syndrome: pharmacotherapeutic considerations. Expert Rev Clin Pharmacol. 2013;6(2):197-219.

\section{Publisher's Note}

Springer Nature remains neutral with regard to jurisdictional claims in published maps and institutional affiliations. 